\title{
Hyperbaric oxygen and cancer: more complex than we expected
}

\author{
Liu Wenwu • Sun Xuejun • Tao Hengyi • Liu Kan
}

Received: 18 December 2012 / Accepted: 14 January 2013 / Published online: 24 January 2013

(C) Springer-Verlag France 2013

Hyperbaric oxygen (HBO) therapy refers to the breathing of pure oxygen while in a sealed chamber that has been pressurized at 1.5 to 3 times normal atmospheric pressure. To date, HBO therapy has been applied in a series of diseases with potential hypoxia including decompression sickness, carbon monoxide poisoning, gas gangrene, osteomyelitis, and so on (http://en.wikipedia.org/wiki/Hyperbaric_medicine). However, cancer is not an indication for hyperbaric oxygen in both USA and China.

Recently, Moen and Stuhr reviewed the evidence on the influence of HBO on cancers in past 9 years [1]. Their conclusion was consistent with two previous systemic reviews on $\mathrm{HBO}$ and cancer that the use of $\mathrm{HBO}$ in patients with malignancies is considered safe. In this review, they summarized the relationship between hypoxia and cancer and the influence of HBO on cell survival, angiogenesis, metastasis, chemotherapy, and radiotherapy. Finally, they reviewed the effect of HBO on cancer cells of different types. Although they proposed some explanations on the effects of HBO on cancers, the mechanisms are more complex than we expected.

\section{HBO, hypoxia, and angiogenesis}

It has been accepted that HBO can increase the dissolved oxygen significantly, which may rectify the hypoxia in

\footnotetext{
L. Wenwu $\cdot$ S. Xuejun $(\triangle) \cdot$ T. Hengyi $\cdot$ L. Kan

Department of Diving Medicine,

Second Military Medical University,

Room 909, Military Building,

No. 800 Xiangyin Road, Yangpu District,

Shanghai 200433, China

e-mail:sunxjk@hotmail.com

T. Hengyi

Institute of Nautical Medicine, Nantong University,

Jiangsu 226019, People's Republic China
}

cancers. However, HBO is often used once or twice daily for patients, and a hypoxic environment may form between two exposures. As shown in this review, hypoxia is essential for the progression of cancers and related to the angiogenesis. In addition, some studies have also shown that HBO therapy can improve the angiogenesis after ischemic injury. Our previous study also revealed that HBO pretreatment can increase the expression of hypoxia-inducible factor and its downstream factor vascular endothelial growth factor [2] which is a potent pro-angiogenic factor. Thus, HBO seems to exert promotive effect on cancer growth.

\section{HBO and metastasis}

Metastasis is a complex process involving local cancer cell invasion, entry into the blood or lymph vessels, and repenetration and colonization at a distant site [3]. The integrity of vascular basement membrane (VBM) is crucial for the cancer cell invasion. Suzuki et al. found that $\mathrm{HBO}$ enhanced transendothelial permeability in rat brains [4]. In addition, HBO preconditioning was found to increase the expression of matrix metalloproteinase (MMP) [5] which is may break the VBM. This may potentiate the cancer cell invasion. Of interest, HBO therapy may reduce the insult-induced expression of MMP [6]. Thus, whether the effect of HBO on VBM integrity depends on the microenvironment is not clear. If so, this may partially explain the absence of influence of $\mathrm{HBO}$ on the metastasis of cancers.

\section{HBO and cancer stem cells}

Cancer stem cells (CSCs) are cancer cells that possess characteristics associated with normal stem cells, specifically 
the ability to give rise to all cell types found in a particular cancer sample (http://en.wikipedia.org/wiki/Cancer_stem_cell). CSCs have been found to be crucial for the recurrence and metastasis of cancers and they mediate the resistance to chemotherapy and/or radiotherapy $[7,8]$. Thus, the therapeutic strategies targeting CSCs may be promising in the treatment of cancers.

In 2006, Thom et al. found that HBO may mobilize the stem cells in a nitric oxide-dependent manner [9]. There are some similarities between CSCs and normal stem cells, and thus, some researchers favor the theory that the CSCs are caused by a mutation in stem cell niche populations during development [10]. However, the influence of HBO exposure on the CSCs is still poorly understood. If HBO exposure mobilizes the CSCs as it influences on normal stem cells, HBO therapy has the potential to mediate the metastasis and recurrence of cancers and their resistance to therapies. More studies are needed to elucidate it.

\section{HBO and chemotherapy/radiotherapy}

One of the mechanisms underlying the therapeutic effects of chemotherapy/radiotherapy is closely related to the production of reactive oxygen species (ROS) after therapies. However, studies have also confirmed that HBO exposure has the potential to increase ROS which is also related to the therapeutic effect of HBO [11]. Thus, combined use of chemotherapy/radiotherapy and HBO might increase the toxicity leading to the injury to not only cancer cells, but also normal cells. Investigators propose that chemotherapy and/or radiotherapy is performed after HBO exposure $[12,13]$. However, no enough evidence supports this regimen.

\section{HBO and autophagy}

Autophagy refers to a cellular degradation pathway for the clearance of damaged or superfluous proteins and organelles [14]. It is now clear that surviving metabolic stress in vitro and in cancers in vivo is dependent on autophagy, and the ability to inhibit autophagy and sensitize even apoptosisresistant cancer cells to metabolic stress is a promising avenue for cancer therapy [15]. Wang et al. hypothesized that hyperoxia preconditioning could exert neuroprotective effect in an autophagy-dependent manner [16], and this hypothesis was confirmed in a recent study in which the autophagy was enhanced in cerebral ischemia rats receiving hyperoxia preconditioning [17]. Whether the activation of autophagy occurs after HBO exposure in cancer patients is unclear.
Although the available evidence does not support that HBO therapy may promote the cancer progression, the specific influence of $\mathrm{HBO}$ on the biological behaviors of cancer cells should be confirmed in future studies, especially in clinical trials. The mechanisms underlying the influence of HBO on cancer cells are complex beyond we expected, and more investigations are required to elucidate them.

Conflict of interest We declare that there is no conflict of interest in this paper.

\section{References}

1. Moen I, Stuhr LE (2012) Hyperbaric oxygen therapy and cancer-a review. Target Oncol 7(4):233-42

2. Ren P, Kang Z, Gu G, Liu Y, Xu W, Tao H, Zhang JH, Sun X, Ji H (2008) Hyperbaric oxygen preconditioning promotes angiogenesis in rat liver after partial hepatectomy. Life Sci 83(7-8):236-41

3. van Zij1 F, Krupitza G, Mikulits W (2011) Initial steps of metastasis: cell invasion and endothelial transmigration. Mutat Res 728(1-2):23-34

4. Suzuki Y, Tanaka K, Neghishi D, Shimizu M, Murayama N, Hashimoto T, Yamazaki H (2008) Increased distribution of carboplatin, an anti-cancer agent, to rat brains with the aid of hyperbaric oxygenation. Xenobiotica 38(12):1471-5

5. Ostrowski RP, Jadhav V, Chen W, Zhang JH (2010) Reduced matrix metalloproteinase-9 activity and cell death after global ischemia in the brain preconditioned with hyperbaric oxygen. Acta Neurochir Suppl 106:47-9

6. Vlodavsky E, Palzur E, Soustiel JF (2006) Hyperbaric oxygen therapy reduces neuroinflammation and expression of matrix metalloproteinase-9 in the rat model of traumatic brain injury. Neuropathol Appl Neurobiol 32(1):40-50

7. Hermann PC, Huber SL, Herrler T, Aicher A, Ellwart JW, Guba M, Bruns CJ, Heeschen C (2007) Distinct populations of cancer stem cells determine tumor growth and metastatic activity in human pancreatic cancer. Cell Stem Cell 1(3):31323

8. Malik B, Nie D (2012) Cancer stem cells and resistance to chemo and radio therapy. Front Biosci (Elite Ed) 4:2142-9

9. Thom SR, Bhopale VM, Velazquez OC, Goldstein LJ, Thom LH, Buerk DG (2006) Stem cell mobilization by hyperbaric oxygen. Am J Physiol Heart Circ Physiol 290(4):H1378-86

10. Bjerkvig R, Tysnes BB, Aboody KS, Najbauer J, Terzis AJ (2005) Opinion: the origin of the cancer stem cell: current controversies and new insights. Nat Rev Cancer 5(11):899-904

11. Zhang X, Xiong L, Hu W, Zheng Y, Zhu Z, Liu Y, Chen S, Wang X (2004) Preconditioning with prolonged oxygen exposure induces ischemic tolerance in the brain via oxygen free radical formation. Can J Anaesth 51(3):258-63

12. Kohshi K, Kinoshita Y, Imada H, Kunugita N, Abe H, Terashima H, Tokui N, Uemura S (1999) Effects of radiotherapy after hyperbaric oxygenation on malignant gliomas. Br J Cancer 80 $(1-2): 236-41$

13. Moen I, Tronstad KJ, Kolmannskog O, Salvesen GS, Reed RK, Stuhr LE (2009) Hyperoxia increases the uptake of 5-fluorouracil in mammary tumors independently of changes in interstitial fluid 
pressure and tumor stroma. BMC Cancer 9:446. doi:10.1186/14712407-9-446

14. Levine B, Klionsky DJ (2004) Development by self-digestion: molecular mechanisms and biological functions of autophagy. Dev Cell 6(4):463-77

15. Mathew R, Karantza-Wadsworth V, White E (2007) Role of autophagy in cancer. Nat Rev Cancer 7(12):961-7
16. Wang YC, Zhang S, Du TY, Wang B, Sun XQ (2010) Hyperbaric oxygen preconditioning reduces ischemia-reperfusion injury by stimulating autophagy in neurocyte. Brain Res 1323:149-51

17. Yan W, Zhang H, Bai X, Lu Y, Dong H, Xiong L (2011) Autophagy activation is involved in neuroprotection induced by hyperbaric oxygen preconditioning against focal cerebral ischemia in rats. Brain Res 1402:109-21 